\title{
UNA IMAGEN SOBRE LA EDUCACIÓN ARTÍSTICA EN LA ACTUALIDAD
}

\author{
A portrait about the Artistic Education at the present time
}

SILVA, Brigite ${ }^{1}$; OLIVEIRA, Mónica ${ }^{2}$

\begin{abstract}
Resumen
Es innegable la importancia de la Expresión Plástica en el crecimiento global del niño, con todo, intervinientes en el proceso didáctico y muchos teóricos consideran que el arte en la educación se encuentra en una posición menospreciada (BARBOSA, 2001, 2002; EFLAND, 2002, 2004; HERNÁNDEZ, 2000; MARTINS, 2002; LÓPEZ GARCÍA, 2003; OLIVEIRA et al., 2004; WAGNER, 2001). Estas consideraciones llevan a cuestionar las prácticas pedagógicas de los educadores infantiles, la forma como desarrollan su currículo, las oportunidades educativas que ofrecen a los niños, o sea, importa percibir si la Expresión Plástica se desenvuelve con calidad pedagógica en contextos de Educación Infantil. En este sentido, el problema planteado conduce a la necesidad de conocer nuestra realidad y a presentar caminos congruentes con el tiempo en el que vivimos, donde el concepto de arte e imagen invaden y amplían nuestras experiencias cotidianas que necesitan ser descodificadas para que sean entendidas. Así, este trabajo pretende exponer un diagnóstico de las prácticas educativas ejecutadas por educadores infantiles del distrito de Oporto (Portugal) en el dominio de la Expresión Plástica.
\end{abstract}

\begin{abstract}
The importance of the Plastic Expression in the global development of the child is undeniable, nevertheless, participants in the didactic process and theoretical people think that art in education is in a despised position (BARBOSA, 2001, 2002; EFLAND, 2002, 2004; HERNÁNDEZ, 2000; MARTINS, 2002; LÓPEZ GARCÍA, 2003; OLIVEIRA et al., 2004; WAGNER, 2001). These perspectives lead to questioning the pedagogical practices of early childhood educators, the way in which they develop the curriculum, the educational opportunities that they offer children, thus attempting to understand if the domain of Plastic Expression develops with pedagogical quality within the context of early childhood education. In this sense, the problem raised leads to the need to comprehend our reality and present ways that are coherent with the times in which we live, where the concept of art and image invade and extend our daily experiences and for them to be understood they need to be deciphered. This article intends to present a diagnosis of the educational practices of early childhood educators of the district of Oporto (Portugal) in the domain of the Plastic Expression.
\end{abstract}

Palabras-clave: Expresión Plástica, Educación Infantil, prácticas pedagógicas.

Keywords: Plastic expression, early childhood education, pedagogical practices

Data de submissão: Janeiro de 2013 | Data de publicação: Março de 2013.

1 BRIGITE CARVALHO DA SILVA - Escola Superior de Educação de Paula Frassinetti. Correio eletrónico: brigite.silva@esepf.pt. Portugal.

${ }^{2}$ SANDRA MÓNICA FIGUEIREDO DE OLIVEIRA - Escola Superior de Educação de Paula Frassinetti. Correio eletrónico: monica@esepf.pt. Portugal. 


\section{LAS ARTES VISUALES EN LA EDUCACIÓN INFANTIL: NUEVOS RETOS}

La contemporaneidad social, tecnológica y cultural solicita a la constante redefinición del arte alertando a la necesidad de un nuevo concepto de cultura visual:

"El término 'cultura visual' abarca la forma de muchos medios que van desde obras de arte como el cine popular y la televisión a la publicidad visual en campos como las ciencias, derecho y medicina... las [imágenes visuales] son fundamentales por la forma como representan el significado y comunican con el mundo que nos rodea" (STURKEN \& CARTWRIGHT, 2001, p. 1).

La necesidad de una alfabetización visual implica incluir esta nueva perspectiva en la escuela (BARBOSA, 2002, p. 18) de forma a permitir una lectura consciente y crítica de las imágenes que nos son presentadas por nuestro entorno. En una aproximación antropológica, las imágenes visuales son apreciadas según el contexto cultural en que son producidas (¿Para qué finalidad la imagen visual fue producida? ¿Para quién fue hecha? ¿Dónde fue colocada originalmente?, etc.) (PARK, 2006).

La defensa de la cultura visual en la educación encuentra fuerza en el reconocimiento de la importancia de las imágenes visuales en la transmisión de valores y actitudes culturales. El arte es capaz de llevar "el sujeto a aprender y analizar la realidad del medio ambiente, insertándolo en el lugar a lo cual pertenece y posibilitándole aún la realidad aprehendida” (BIASOLI, 1999, p. 92). Ante este mundo visual, la expresión plástica podrá tener un papel importante en el desarrollo de la capacidad de analizar, interpretar y apreciar todo el tipo de imágenes, de arte o no, y proporcionar estrategias para crearlas pues "El ciudadano del futuro deberá ser un receptor consciente y un productor eficaz de imágenes y/u obras de arte." (CAJA, BERROCAL \& RAMOS, 2003, p. 39). Así, “... plantear la comprensión de la cultura visual en la escuela no responde a un esnobismo sino a una necesidad." (HERNÁNDEZ, 2003, p. 46). No se trata únicamente de interpretar imágenes, sino de emplazarlas en el panorama social, teniendo en consideración la identidad, la memoria y la imaginación de los grupos y de las personas (HERNÁNDEZ, 2003). 
De hecho, es importante percibir la dirección que este dominio ha tomado en la Educación Infantil con el objetivo de contribuir de forma efectiva para el conocimiento en pedagogía del arte y a la consecuente mejora de las prácticas educativas a través de instrumentos de orientación más concretos para los educadores infantiles.

\section{METODOLOGÍA Y OBJETIVOS DE LA INVESTIGACIÓN}

La investigación tuvo como primer objetivo comprender cuáles son las premisas básicas que un educador infantil debe tener en cuenta para llevar a cabo un trabajo de calidad en el campo de la Expresión Plástica para, posteriormente, analizar el tipo de prácticas desarrolladas por un conjunto de educadores infantiles, creando y suministrando instrumentos que sirvan de monitorización a las prácticas educativas.

En este sentido, el problema planteado conduce a la necesidad de responder a diferentes objetivos de pesquisa que guiarán la estructura y desarrollo de esta investigación, más concretamente la organización metodológica del estudio. Así, los objetivos del estudio son los siguientes:

1 - Conocer las directrices para una práctica educativa adecuada de la Expresión Plástica en la Educación Infantil;

2 - Examinar de qué modo la Expresión Plástica es desarrollada en contextos de Educación Infantil;

3 - Verificar si un referencial de calidad que contemple diferentes dimensiones curriculares (espacio y materiales, tiempo, interacciones, etc.), es pertinente para apoyar a la intervención de los educadores infantiles en el dominio de la Expresión Plástica;

4 - Identificar cuáles son las acciones formativas esenciales para ayudar a los educadores infantiles a mejorar sus prácticas.

Este trabajo de investigación integra dos estudios complementarios que se apoyaron en pesquisas bibliográficas, lecturas críticas y búsquedas de proyectos de investigación e intervención ya existentes en el panorama educativo de modo a intentar, en una primera fase exploratoria, diagnosticar a través de la recogida de datos, la trayectoria del desarrollo de la Expresión Plástica por educadores infantiles portugueses y, en una segunda fase, de acuerdo con 
los datos recogidos en el periodo exploratorio, se construyó un instrumento de evaluación de la calidad educativa en el dominio de la Expresión Plástica para percibir las prácticas efectivas de los educadores y para valer, también, de instrumento auxiliador en la regulación de su propia intervención educativa. Asimismo, fueran realizadas sesiones formativas que pretendieron apoyar a los educadores a alcanzar mayores niveles de calidad. Se procedió, además, al análisis de las planificaciones de los educadores infantiles para comprender las oportunidades educativas que ellos desarrollaron en el campo de la Expresión Plástica auxiliando a la articulación de datos.

Se utilizó una metodología basada en la investigación-acción, pues "el objeto de la investigación-acción constituye la transformación de la práctica educativa y/o social, al mismo tiempo que se procura una mayor comprensión de la misma” (PINA, 1994, p. 379), y así esto se constituyó el elemento central para la recogida y tratamiento de información de la presente investigación.

\section{DIAGNOSTICANDO LA REALIDAD EDUCATIVA: CARACTERIZACIÓN DEL ESTUDIO 1}

\subsection{Muestra, instrumentos y técnicas de recogida de datos del estudio exploratorio}

La muestra en el estudio exploratorio era compuesta por 108 educadores de jardines infantiles del distrito de Oporto (Portugal), elegida por un muestreo de conveniencia donde se seleccionó a los miembros de la población más accesibles de cara a la obtención de información (CARMO \& FERREIRA, 1998; SOUSA, 2009). Es necesario destacar que no se pretendió una representatividad estadística de este universo con la finalidad de generalizar los resultados obtenidos, sino una intencionalidad teórica de modo a alcanzar los objetivos de esta investigación. Se realizó una encuesta por cuestionario que, de acuerdo con los objetivos de la pesquisa, estuvo compuesto por un total de 24 cuestiones distribuidas por cinco dimensiones: 1 . Identificación socio-profesional - considera variables como el género, edad, grado académico, situación profesional y la búsqueda de acciones formativas realizadas por los educadores en el dominio de la Expresión Plástica; 2. Las artes plásticas y el educador - se centra en la postura (a nivel del discurso como de la práctica) de estos profesionales frente a la Expresión Plástica; 3. La Expresión Plástica en la Educación Infantil - hace referencia a las representaciones que los educadores construyen acerca de esta área curricular; 4. Organización curricular de la Expresión 
Plástica - tiene en cuenta los objetivos, contenidos y metodologías curriculares desarrolladas por los educadores, las divergencias y/o convergencias entre los discursos y las prácticas efectivamente desenvueltas; 5. Recursos materiales y condiciones de trabajo - considera los equipamientos, materiales didácticos y soportes para la concretización de las actividades de Expresión Plástica.

\subsection{Presentación de los resultados del estudio 1}

De forma sintetizada, a partir de los dados recogidos en este estudio exploratorio, observamos que:

- Los educadores realizan muy pocas acciones formativas $(56,5 \%$ respondieron negativamente);

- Los educadores tienen interés en formarse $(85,2 \%)$, sobre todo, a nivel de técnicas $(55,6 \%)$, más que acerca de pedagogía del arte (13\%);

- Los educadores valoran mucho la área de la Expresión Plástica (97\%) con todo dan esencialmente relevancia al arte como libre creación (50,9\%) y apenas 2,8\% dan importancia a actividades de observación, análisis y reflexión sobre la cultura visual;

- Los educadores tienen en consideración la sensibilidad estética en las planificaciones $(28,7 \%)$ sin embargo, frecuentan pocos espacios de arte con los niños (5,6\% van a los museos);

\section{CONSTRUCCIÓN DE UNA "BRÚJULA" PARA LA EXPRESIÓN PLÁSTICA: CARACTERIZACIÓN DEL ESTUDIO 2}

\subsection{Muestra, instrumentos y técnicas de recogida de datos}

Después del estudio exploratorio se construyó un instrumento nombrado de "Instrumento de Evaluación de la Calidad Educativa en el área de Expresión y Comunicación: dominio de la Expresión Plástica - Educación Preescolar" (IAQEP - PE) ${ }^{3}$ para percibir las prácticas efectivas

3 En portugués: Instrumento de Avaliação da Qualidade na área da Expressão e Comunicação: domínio da Expressão Plástica - Educação Pré-escolar 
de los educadores y servir, también, de instrumento auxiliador en la regulación de sus propias prácticas educativas. Así, con este instrumento se pretendió, por un lado, recoger datos sobre las prácticas educativas de los educadores implicados en el estudio percibiendo cuáles son sus conocimientos y comportamientos por lo que respecta al dominio de la Expresión Plástica. Por otro lado, se pretendía que este instrumento permitiese al educador reflexionar sobre la calidad estructural del contexto, sobre las oportunidades de aprendizaje que ofrece e interacciones que establece con el niño, conduciendo, de esta manera a su desarrollo profesional. En este estudio la población estaba constituida por un total de 86 educadores infantiles, insertados en instituciones que reciben a los alumnos de prácticas en educación infantil de una Escuela Superior de Educación, y que trabajaban con niños de los 3 a los 5 años.

El instrumento poseía 54 ítems que tenían que ser clasificados según 3 niveles: A - ítem cumplido totalmente; B - ítem casi cumplido; incompleto; necesita mejoras; C - ítem no cumplido; situación nunca realizada.

Estando el instrumento constituido por estos diferentes ítems, que se encuentran distribuidos por distintas categorías correspondientes a las dimensiones curriculares de la pedagogía de la infancia, el siguiente cuadro sintetiza los aspectos relacionados con la calidad de los ambientes educativos en el ámbito de la Expresión Plástica explorados en el IAQEP-PE.

Cuadro 1 - Categorías del Instrumento de Evaluación de la Calidad Educativa en el área de Expresión y Comunicación: dominio de la Expresión Plástica-Educación Preescolar

Categorías Relacionados con: los espacios destinados al desarrollo de actividades de Expresión Plástica;

A. Organización del espacio y materiales

B. Tiempo

\section{Ítems} la organización del espacio proporcionando el ejercicio de actividades de observación, de manipulación de materiales e instrumentos, y de creación; las posibilidades de exposición de las creaciones de los niños; la accesibilidad de los materiales; la existencia y variedad de materiales.

Relacionados con: la cantidad de tiempo destinado al desarrollo de actividades de Expresión Plástica; el tiempo destinado a la planificación y revisión del trabajo. 


\begin{abstract}
C. Interacción
(Sensibilidad,

Estimulación y

Autonomía)

Actividades y

Proyectos

E. Observación y

evaluación

Relacionados con: la promoción de sentimientos de auto-estima, conforto, seguridad y bienestar; atención a las necesidades e intereses individuales del niño; la promoción de situaciones de creatividad y sensibilidad; las oportunidades de convivencia y de interacción con los adultos y los pares; el estimulo facultado por la planificación individual/ grupal de los niños; el apoyo concedido en el desarrollo del trabajo de los niños.

Relacionados con: la planificación de actividades promotoras a la evolución de capacidades perceptivas, manipulativas y procedimentales, para el conocimiento del patrimonio artístico y

cultural; la planificación de actividades de creación plástica con base en trabajos de proyecto; el desarrollo de actividades y aprovechamiento de periodos de tiempo para la apreciación y reflexión sobre imágenes del cotidiano y artefactos populares, hacer la documentación con los niños recurriendo a diferentes técnicas para planificación y registro de los aprendizajes; la interacción con instituciones culturales y artísticas.

Relacionados con: instrumentos de evaluación auténtica; evaluación de conocimientos, capacidades, actitudes y disposiciones relacionadas con la Expresión Plástica; la evaluación de capacidades perceptivas, del conocimiento del patrimonio artístico y cultural, del desarrollo de capacidades manipulativas, procedimentales y creativas.
\end{abstract}

En este sentido, se considera que un referencial de calidad permite a los educadores una orientación más concreta para sus prácticas permitiendo un auto-análisis más dirigido, sin limitar la gestión autónoma del currículo. Esta consciencia debe estar hecha en función de un progreso armonioso del niño.

De forma sucinta, para el esbozo del IAQEP - PE, las reglas básicas subyacentes fueran las siguientes:

-El arte en la educación debe ser considerado fuerte promotor del desarrollo integral de los niños (desarrollo cognitivo, pensamiento crítico, reflexivo y creativo; etc.) (cf. EFLAND, 2004);

-El aprendizaje artístico no puede ser solamente considerado consecuencia de la maduración pues es necesario un estímulo del profesor a diferentes niveles: en la organización de los espacios y materiales, en la organización del tiempo, en la interacción que establece con los niños, en las actividades que planifica y desarrolla, etc. (cf. VYGOTSKY, 1978); 
-El arte en la educación debe abarcar mucho más que la componente productiva incluyendo aspectos históricos, críticos, estéticos y de interpretación de imágenes, etc. (cf. FREEDMAN \& STUHR, 2004; HERNANDEZ, 1997; BARBOSA, 2005);

-Los currículos deben tener en cuenta los contextos y los intereses de los niños, en una perspectiva interdisciplinar de articulación con la metodología del proyecto; (HERNANDEZ, 2000; HOHMANN \& WEIKART, 2003; KATZ \& CHARD, 1997);

-Una pedagogía del arte debe ser activa, constructivista (cf. HOHMANN \& WEIKART, 2003);

-El arte en la educación no pretende la creación de artistas sino de seres letrados artística y culturalmente (cf. HERNÁNDEZ, 2000; PARK, 2006; BARBOSA, 2002, 2005);

-Un modelo de currículo debe ser considerado como una hipótesis capaz de ser ajustada por el profesor, entendido como proceso (cf. EFLAND, 2000; HERNÁNDEZ, 1998, 2003; PARSONS, 2004).

\subsection{Presentación de los resultados de la $1^{\text {a }}$ aplicación del IAQEP - PE}

En síntesis, los datos recogidos en la $1^{\mathrm{a}}$ aplicación del IAQEP - PE permitieron verificar que:

-En cuanto al grado de seguridad de los educadores en relación a diferentes vertientes de la práctica pedagógica en el ámbito de la Expresión Plástica:

- Los educadores sienten mayor seguridad en el desarrollo de técnicas plásticas (98\%) y menor seguridad en la esfera de la pedagogía del arte (58\%) y en relación a conocimientos sobre el patrimonio artístico (39\%).

-En lo que respecta a aspectos críticos relacionados con la organización del espacio y materiales:

- La mayoría de los educadores indica que no existe un espacio para la exposición de trabajos tridimensionales (46\% - B [ítem casi cumplido]; 26\% - C [ítem no cumplido; situación nunca realizada]) y señalan que son más limitados los materiales que permitan la realización de construcciones tridimensionales. 
-Con relación a vertientes críticas correspondientes a la apreciación de obras de arte y al conocimiento artístico y cultural:

- Los educadores, en su mayoría, no poseen en la sala libros, juegos o catálogos con imágenes de obras de arte $(65 \%$ - C), otorgan mayor importancia a actividades de observación de la naturaleza en oposición a las actividades de observación de obras de arte y, de forma general, casi no llevan los niños a visitar museos u otras instituciones culturales $(48 \%-\mathrm{C} ; 41 \%-\mathrm{B})$.

- Solamente un reducido número de educadores planifica actividades de observación a través de imágenes de obras de arte (material didáctico, fotografías, juegos, etc.) (26\% - A; $37 \%$ - B; $28 \%$ - C) y la mayoría de los educadores no desarrolla actividades que potencien el conocimiento sobre el patrimonio cultural y artístico.

- En la evaluación de los aprendizajes, los educadores tienen en menor consideración aspectos como el conocimiento relacionado con imágenes y obras de arte, la capacidad de diálogo y reflexión sobre imágenes y el gusto por la apreciación de obras.

-En los aspectos críticos relacionados con la organización del tiempo:

- La mayoría de los educadores afirma prever un tiempo diario para que los niños puedan planear (41\% - B; $2 \%$ - C) y volver a ver las actividades de Expresión Plástica $(32,6 \%-B ; 7 \%-C)$ a pesar de que muchos educadores afirman que necesitan mejorar estos aspectos.

-En cuanto a puntos críticos relacionados con el tipo de interacción:

- Los educadores, sobre todo, señalan que valoran situaciones de creatividad y que muestran sensibilidad por la diferencia en la creación artística y tienen en cuenta los intereses de los niños cuando planifican las actividades en el ámbito de la Expresión Plástica.

- Los educadores estimulan poco la utilización de diferentes técnicas simultáneamente $(67 \%$ - A; $33 \%$ - B).

-Relativamente a aspectos críticos correspondientes a la observación y evaluación: 
- Los educadores evalúan a los niños en el dominio de la Expresión Plástica. Los educadores responden muy positivamente cuando se trata de evaluar capacidades de expresión creativa $(96 \%$ - A), capacidades perceptivas $(84,8 \%$ - A), vocabulario relacionado con las artes plásticas $(84,8 \%)$ y capacidades manipulativas y procedimentales $(83 \%$ - A) pero no tienen mucho en consideración el conocimiento relacionado con imágenes y obras de arte (30,4\% - A; 41,3\% - B; 28,3\% - C), la capacidad de diálogo y reflexión sobre imágenes y arte $(35 \%$ - A; 30\% - B; 35\% - C) y el gusto por la apreciación de las obras artísticas (28,3\% - A; 41,3\% - B; 30,4\% - C).

Los datos recogidos permiten observar de forma muy evidente la ausencia de una intervención pedagógica en el ámbito de la apreciación de obras de arte. Reflexionando sobre las razones para tal laguna, observamos que se trata de un aspecto para el cual los educadores no se sienten preparados o, al revés, no le conceden importancia en el desarrollo de su práctica educativa.

En este sentido, es importante que cualquier intervención con vista a mejorar las prácticas educativas de estos educadores se focalice en los aspectos críticos destacados en las respuestas al IAQEP - PE. Así, es necesario que los educadores tomen conciencia de la importancia del arte en la Educación Infantil para que después enriquezcan el ambiente físico con imágenes artísticas, concretamente a través de libros, juegos o catálogos con imágenes de obras de arte, para que visiten con los niños museos u otras instituciones culturales, para que desarrollen actividades de observación a través de obras de arte e incrementen actividades que potencien el conocimiento sobre el patrimonio cultural y artístico. De este modo, importa que tengan en consideración en la evaluación aspectos como el conocimiento relacionado con imágenes y obras de arte, la capacidad de diálogo y reflexión sobre imágenes y el gusto por la apreciación de obras.

Estos datos están en consonancia, en diferentes aspectos, con los datos obtenidos en el estudio exploratorio.

\subsection{El dibujo de un camino: plan de formación}

Teniendo como base los datos recogidos en la $1^{\mathrm{er}}$ aplicación del IAQEP- PE, surge la necesidad de promover en los educadores infantiles un mayor conocimiento acerca de las vertientes de intervención pedagógica en el dominio de la Expresión Plástica. En este ámbito, la 
acción formativa se centró, de forma más incisiva, en una tentativa de aumentar el conocimiento de los educadores entorno de la apreciación de obras de arte con niños con vista a mejorar la calidad de las prácticas educativas.

De este modo, en la programación de diferentes momentos formativos, se estableció como objetivo principal proporcionar a los educadores momentos de reflexión sobre las prácticas en el ámbito de la Expresión Plástica, partiendo del conocimiento de fundamentos psicopedagógicos de la Expresión Plástica. En este sentido, se establecieron como objetivos específicos:

-Dar a conocer fundamentos en el caso de la pedagogía del arte y relacionados con conocimientos sobre el patrimonio artístico.

-Desarrollar la conciencia acerca de la importancia de la apreciación de imágenes y obras de arte con niños:

- Potenciar un mayor conocimiento sobre las posibilidades pedagógicas de las visitas a museos y otros equipamientos culturales;

- Incentivar el desarrollo de actividades que potencien el conocimiento sobre el patrimonio cultural y artístico;

- Incentivar el desarrollo de actividades de observación y apreciación en el propio contexto de Educación Infantil a través de reproducciones de imágenes y obras de arte (material didáctico, fotografías, juegos, etc.);

- Dar a conocer la importancia de una evaluación de los aprendizajes que considere aspectos como el conocimiento relacionado con imágenes y obras de arte, la capacidad de diálogo y reflexión sobre imágenes y el gusto por la apreciación de obras.

-Reforzar la conciencia sobre aspectos pedagógicamente relevantes en la organización del espacio y los materiales:

- Destacar la importancia de poseer diversidad de materiales para construcciones tridimensionales y de exponer los trabajos tridimensionales de los niños.

Las sesiones formativas disponibles para los educadores eran, naturalmente, de carácter facultativo sin obligatoriedad de participación. La invitación a las sesiones formativas, comunicando la fecha, el formador y el local donde transcurriría la formación, fue llevada a cabo 
de tres formas diferentes: a través de la página Web de la Escuela Superior de Educación; a través de un espacio en una plataforma de enseñanza a distancia utilizada para la comunicación entre las instituciones de práctica cooperantes y la institución de enseñanza superior; a través de una carta y díptico enviados por correo a cada uno de los educadores.

La planificación de las sesiones tuvo en cuenta, de forma muy concreta, las necesidades formativas identificadas a partir de la primera aplicación del IAQEP- PE.

Cuadro 2 - Contenidos de las sesiones formativas

\begin{tabular}{|c|c|c|}
\hline $\begin{array}{c}\text { Designación de } \\
\text { la acción }\end{array}$ & $\begin{array}{c}\text { Temática de la } \\
\text { formación }\end{array}$ & Contenidos de la formación \\
\hline $\begin{array}{l}\text { El dibujo del } \\
\text { niño y la } \\
\text { expresividad } \\
\text { emocional }\end{array}$ & $\begin{array}{l}\text { Dibujo del niño e } \\
\text { intervención del } \\
\text { educador }\end{array}$ & $\begin{array}{l}\text {-Importancia del dibujo con su valor intrínseco para la expresión emocional del } \\
\text { niño } \\
\text {-Aspectos a cuidar sobre la interpretación del dibujo del niño y para la importancia } \\
\text { de un clima que fomente confianza } \\
\text {-Atención para evitar una concepción del arte como don individual influido por la } \\
\text { afirmación, expuesta de forma exageradamente precoz, de tener aptitud o falta de } \\
\text { aptitud para dibujar } \\
\text {-Importancia de experiencias culturales para el desarrollo del niño } \\
\text {-Importancia de que el educador investigue y se documente sobre saberes } \\
\text { culturales y artísticos no sólo por los efectos en el área específica, sino a nivel } \\
\text { general, en el proceso de desarrollo }\end{array}$ \\
\hline $\begin{array}{l}\text { Un viaje } \\
\text { pedagógico por } \\
\text { el mundo del } \\
\text { arte (sesión I y } \\
\text { sesión II) }\end{array}$ & $\begin{array}{l}\text {-Posibilidades } \\
\text { pedagógicas que el } \\
\text { museo ofrece y de qué } \\
\text { modo se puede } \\
\text { explorarlas con los } \\
\text { niños }\end{array}$ & $\begin{array}{l}\text {-Importancia de conceder una experiencia positiva a los niños en la visita al } \\
\text { museo. } \\
\text {-Importancia del acceso al conocimiento artístico y cultural para el desarrollo de la } \\
\text { sensibilidad } \\
\text {-Importancia de una perspectiva que incorpore diferentes dimensiones sensitivas } \\
\text { en la intervención con los niños } \\
\text {-Importancia de los museos como locales inspiradores de nuevas formas de } \\
\text { comunicar } \\
\text {-Importancia de una preparación previa para la visita al museo junto con los } \\
\text { servicios de educación del museo- } \\
\text {-El papel del educador en la propia dinamización de la visita al museo y en la }\end{array}$ \\
\hline
\end{tabular}




\begin{tabular}{|c|c|c|}
\hline & & $\begin{array}{l}\text { amplitud de posibilidades de trabajo con los niños que el museo ofrece } \\
\text {-Nociones básicas que pueden ser trabajadas en una visita con los niños al museo } \\
\text { (tamaño; nociones de escala; la construcción de las cosas; los materiales } \\
\text { envueltos; el color; el estilo; etc.) } \\
\text {-Asociación de las obras de arte del museo al trabajo del proyecto vivido } \\
\text {-Importancia de desarrollar la capacidad de los educadores para la actuación con } \\
\text { los niños en el museo }\end{array}$ \\
\hline $\begin{array}{l}\text { Calidad de las } \\
\text { prácticas } \\
\text { educativas en el } \\
\text { dominio de la } \\
\text { Expresión } \\
\text { Plástica }\end{array}$ & $\begin{array}{l}\text {-Aspectos base para la } \\
\text { calidad de las } \\
\text { prácticas educativas } \\
\text { en el dominio de la } \\
\text { Expresión Plástica }\end{array}$ & $\begin{array}{l}\text {-La importancia del arte en la educación } \\
\text {-Panorama de la educación artística } \\
\text { - dificultades actuales en la educación artística } \\
\text { - Expresión Plástica en las Orientaciones Curriculares para la Educación } \\
\text { Infantil } \\
\text { - aspectos clave para el desarrollo del aprendizaje y del currículo: perspectivas } \\
\text {-La Expresión Plástica y las dimensiones curriculares de la pedagogía de la } \\
\text { infancia } \\
\text { - organización del espacio y materiales; organización del tiempo; interacción; } \\
\text { actividades y proyectos; observación y evaluación } \\
\text {-Apreciación de obras de arte } \\
\text { - disposiciones del pensamiento artístico } \\
\text { - propuesta de observación de obras de arte con niños } \\
\quad \text { - enfoque VTS (Visual Thinking Strategies) } \\
\text {-Cambio de experiencias entre las alumnas }\end{array}$ \\
\hline Trabalh'Art & $\begin{array}{l}\text {-Reparto de la } \\
\text { concepción } \\
\text { pedagógica defendida } \\
\text { por una escuela } \\
\text {-Reparto de } \\
\text { experiencias prácticas } \\
\text { de apreciación y de } \\
\text { creación teniendo } \\
\text { como base diferentes } \\
\text { artistas }\end{array}$ & $\begin{array}{l}\text {-Importancia del sentido crítico y reflexivo } \\
\text {-La perspectiva instrumental y cognitiva de la Expresión Plástica } \\
\text {-El arte en la educación para el desarrollo integral del niño } \\
\text {-Importancia del educador como profesional investigador } \\
\text {-Presentación de experiencias prácticas de apreciación y de creación }\end{array}$ \\
\hline
\end{tabular}


En lo que respecta a la asistencia a las sesiones planificadas para responder a las necesidades de formación identificadas, un $61,63 \%$ de la población realizó algún tipo de formación.

Cuadro 3 - Asistencia de los educadores a las sesiones formativas

\begin{tabular}{|c|c|c|c|c|}
\hline $\begin{array}{c}\text { El dibujo del } \\
\text { niño y la } \\
\text { expresividad } \\
\text { emocional }\end{array}$ & $\begin{array}{c}\text { Un viaje pedagógico } \\
\text { por el mundo del } \\
\text { arte (I) }\end{array}$ & Trabalh'Art & $\begin{array}{c}\text { Calidad de las } \\
\text { prácticas } \\
\text { educativas en el } \\
\text { dominio de la } \\
\text { Expresión } \\
\text { Plástica }\end{array}$ & $\begin{array}{l}\text { Un viaje pedagógico por el } \\
\text { mundo del arte } \\
\text { (II) }\end{array}$ \\
\hline
\end{tabular}

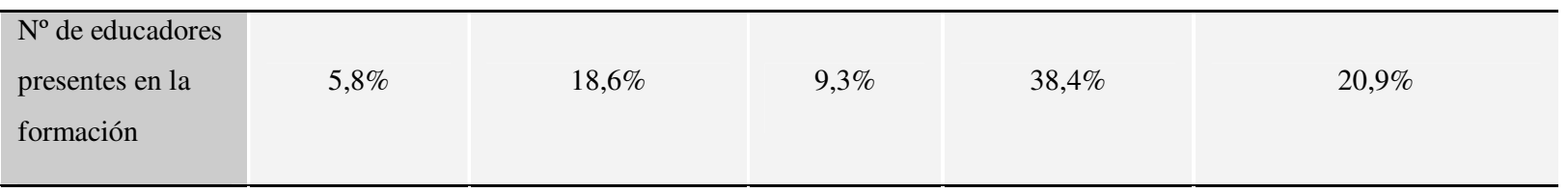

$\mathrm{N}^{\circ}$ total de

educadores

presentes en las

$61,63 \%$

formaciones

Comparación de los resultados de la $1^{\text {er }}$ y de la $2^{a}$ aplicación del IAQEP-PE

El IAQEP-PE fue aplicado de nuevo a la misma población de estudio que en la $1^{\mathrm{a}}$ aplicación del mismo. En esta fase del estudio, de los 86 educadores, respondieron a los cuestionarios 51 educadores.

A través de los datos recogidos podemos observar una subida en la media de las puntuaciones finales. Pero se observa en las dimensiones Planificación/ Actividades y Proyectos y Observación y Evaluación que no se produjeron cambios significativos en relación a la $1^{\mathrm{a}}$ aplicación del IAQEP-PE. En la dimensión Observación y Evaluación los datos recogidos muestran una ligera disminución de la media de las puntuaciones. 
Cuadro 4 - Comparación de las medias obtenidas en la 1er y $2^{\mathrm{a}}$ aplicación del IAQEP-PE

\begin{tabular}{|c|c|c|c|}
\hline & $\begin{array}{c}\text { Medias de la } 1^{\text {er }} \\
\text { Aplicación de lo } \\
\text { IAQEP-PE }\end{array}$ & $\begin{array}{c}\text { Medias de la } 2^{\mathrm{a}} \\
\text { Aplicación de lo } \\
\text { IAQEP-PE }\end{array}$ & Diferencia entre las medias \\
\hline Espacio y materiales & 14,9 & 16,4 & $+1,5$ \\
\hline Tiempo & 16,5 & 17,5 & +1 \\
\hline Interacción & 16,6 & 17,5 & $+0,9$ \\
\hline $\begin{array}{l}\text { Planificación/ actividades y } \\
\text { proyectos }\end{array}$ & 12,6 & 12,8 & $+0,2$ \\
\hline Observación y evaluación & 15,1 & 14,8 & $-0,3$ \\
\hline Media total & 15,1 & 15,8 & $+0,7$ \\
\hline
\end{tabular}

Estos datos pueden revelar que, por parte de los educadores infantiles, hubo una mayor alteración en los aspectos relacionados con las características estructurales del contexto y de los materiales, de la organización del tiempo y de la calidad de las interacciones. Los aspectos asociados a la planificación y desarrollo de actividades y proyectos y a la observación y evaluación son más reacios al cambio.

Podemos observar de forma clara que en la $1^{\mathrm{a}}$ aplicación del IAQEP-PE las clasificaciones finales obtenidas por los educadores se encontraban más dispersas, presentándose un mayor número de educadores con clasificaciones más elevadas, un $19 \%$ entre 18 y 20, y educadores con clasificaciones más bajas, un $28 \%$ entre 10 y 13,9 . En la $2^{\text {a }}$ aplicación se observa una disminución de educadores en estos niveles, es decir, entre 18 y 20 con un $6 \%$ y entre 9 y 13,9 con un $12 \%$. Se constata, así, que en los datos obtenidos en el segundo momento de la aplicación del IAQEP-PE, las clasificaciones se distribuyen esencialmente entre 12 y 18,9, existiendo solamente un $2 \%$ clasificado entre 9 y 9,9 mientras que en la primera aplicación se distribuían entre 10 y 20.

Así, en comparación con los datos obtenidos en la $1^{\mathrm{er}}$ aplicación, se constata el hecho de que en la $2^{\mathrm{a}}$ aplicación hubo un menor número de puntuaciones elevadas (entre 18 y 20) y de puntuaciones inferiores (puntuaciones hasta 13,9) que pueden ser el resultado, por un lado, de una mayor conciencia de los educadores respecto a cada ítem del cuestionario, para no 
sobrevalorar determinadas respuestas y, por otro lado, de una mejora de la calidad efectiva de algunos contextos.

Analizando las respuestas dadas por los educadores en la $1^{\mathrm{er}}$ y $2^{\mathrm{a}}$ aplicación de los cuestionarios con relación al grado de seguridad sentida en las técnicas de Expresión Plástica, al nivel de saberes (pedagógicos y metodológicos) en el ámbito de la pedagogía del arte y con respecto a los conocimientos sobre el patrimonio artístico, se observó que entre las aplicaciones de los cuestionarios, los cambios no fueron significativos. Por lo que respecta al conocimiento sobre técnicas de Expresión Plástica y sobre el patrimonio artístico y cultural, los sentimientos de seguridad e inseguridad de los educadores se mantienen. Se percibe un aumento de sentimientos de seguridad en lo que concierne a los saberes en el ámbito de la pedagogía del arte.

Cuadro 5- Comparación del grado de seguridad sentida a nivel de las técnicas de Expresión Plástica, a nivel de saberes en el ámbito de la pedagogía del arte y a nivel de conocimientos sobre el patrimonio artístico en la 1er y $2^{\text {a }}$ aplicación del IAQEP-PE

\begin{tabular}{|c|c|c|c|c|c|c|}
\hline & \multicolumn{2}{|c|}{$\begin{array}{c}\text { Conocimientos sobre técnicas de } \\
\text { Expresión Plástica }\end{array}$} & \multicolumn{2}{|c|}{$\begin{array}{c}\text { Saberes en el ámbito de la } \\
\text { Pedagogía del arte }\end{array}$} & \multicolumn{2}{|c|}{$\begin{array}{l}\text { Conocimientos sobre el } \\
\text { patrimonio artístico }\end{array}$} \\
\hline & $\begin{array}{c}1^{a} \text { Aplicación del } \\
\text { IAQEP-PE }\end{array}$ & $\begin{array}{l}2^{\text {a }} \text { Aplicación } \\
\text { del IAQEP-PE }\end{array}$ & $\begin{array}{l}\text { 1"Aplicación del } \\
\text { IAQEP-PE }\end{array}$ & $\begin{array}{l}2^{\text {a }} \text { Aplicación } \\
\text { del IAQEP-PE }\end{array}$ & $\begin{array}{l}\text { 1ª Aplicación } \\
\text { del IAQEP-PE }\end{array}$ & $\begin{array}{l}\text { 2a Aplicación del } \\
\text { IAQEP-PE }\end{array}$ \\
\hline Muy seguro & $28 \%$ & $16 \%$ & $4 \%$ & $6 \%$ & $2 \%$ & $2 \%$ \\
\hline Seguro & $70 \%$ & $82 \%$ & $54 \%$ & $61 \%$ & $37 \%$ & $37 \%$ \\
\hline $\begin{array}{lll}\text { Soma de los } \\
\text { niveles } & \text { de } \\
\text { seguranza } & \end{array}$ & $98 \%$ & $98 \%$ & $58 \%$ & $67 \%$ & $39 \%$ & $39 \%$ \\
\hline Inseguro & $0 \%$ & $2 \%$ & $39 \%$ & $33 \%$ & $48 \%$ & $57 \%$ \\
\hline Muy inseguro & $2 \%$ & $0 \%$ & $2 \%$ & $0 \%$ & $13 \%$ & $6 \%$ \\
\hline $\begin{array}{ll}\text { Soma de los } \\
\text { niveles } & \text { de } \\
\text { inseguranza } & \end{array}$ & $2 \%$ & $2 \%$ & $41 \%$ & $33 \%$ & $61 \%$ & $63 \%$ \\
\hline
\end{tabular}

Estos datos no permiten afirmar con toda la convicción que las sesiones formativas y el propio instrumento ayudaron a aumentar el grado de seguridad en este dominio pero se puede observar que, de hecho, hubo un ligero aumento de los sentimientos de seguridad de los educadores y de los propios niveles de calidad después del periodo formativo. 


\section{IMPLICACIONES DE LOS RESULTADOS DE LA INVESTIGACIÓN}

Por lo que se refiere al modo como la Expresión Plástica es desarrollada en contextos de Educación Infantil, los datos recogidos a lo largo de esta investigación, demuestran de forma muy evidente que los educadores infravaloran en sus prácticas educativas una vertiente conectada al conocimiento artístico y cultural, una visión del arte para la comprensión. Parece persistir una concepción relacionada con la autoexpresión creativa, y aún más, una perspectiva que entiende la Expresión Plástica sobre todo como un dominio donde se desarrollan destrezas manuales y se aprenden técnicas plásticas a través de actividades disueltas, vacías de contenidos de carácter cognitivo.

Así, es fundamental cuestionar: “QQué capacidades cognitivas proporcionan las artes que otras materias no pueden proporcionar, o no lo hacen tan bien como las artes? En concreto, ¿qué capacidades especiales aportan las artes visuales a la cognición en su conjunto?” (EFLAND, 2004, p. 212).

Esto implica que el educador asuma "conscientemente una postura reflexiva y analítica frente a lo que constituye su práctica cotidiana, concibiéndola como campo de saber propio a desarrollar y profundizar y no como normativo que sólo se ejecuta sin actuar sobre él" (ROLDÃO, 2000, p. 17). Por eso, es importante que los educadores consideren esta área de conocimiento, conscientes de sus finalidades como el desarrollo de la capacidad de analizar, interpretar y apreciar todo tipo de imágenes y proporcionar estrategias para crear.

Después de los resultados alcanzados con este proyecto surgen aspectos del ámbito de la formación, investigación y de las políticas educativas que consideramos relevantes registrar. Aunque no pretendiendo asumir una postura reductora, frente al diagnóstico efectuado, ocurren cuestiones que se articulan y cuyas respuestas nos pueden hacer comprender de forma más real no solo los datos obtenidos pero sobre todo reflejar sobre el futuro de la expresión plástica en la educación infantil, como por ejemplo: ¿Qué formación es proporcionada a los profesores por las instituciones de enseñanza superior (facilidades y constreñimiento)? ¿Cuál es la investigación desarrollada en el campo de la pedagogía del arte en las instituciones de enseñanza superior? ¿Qué tendencias siguen las actuales políticas educativas, en el contexto portugués e internacional, en el área de la expresión plástica? 
Estas son cuestiones para las cuales no tenemos una respuesta basada en una investigación empírica, pero podemos afirmar que la formación artística debe facultar a los futuros profesores itinerarios artísticos una formación significativa y singular que los incite y los anime a encontrar lugares donde se pueda establecer el diálogo con el arte y la educación desde un punto de vista contemporáneo. La formación inicial de los educadores infantiles debe tener un papel significativo en la sensibilización, motivación y formación de los educadores infantiles para el desempeño de sus funciones en el ámbito de la Educación Artística e ir más allá de la enseñanza de técnicas de forma compartimentada y sin sustentación pedagógica. El desafío en la formación de profesores en el área de la expresión plástica se compone por una posibilidad de construcción de nuevos modos de comprender y hacer, ampliando el repertorio artístico y cultural del futuro profesional de educación.

Es fundamental, así, en la formación inicial, un equilibrio entre los contenidos pedagógicos y artísticos, estableciendo una relación efectiva entre el Arte y la Educación y que el futuro profesor tenga, durante la carrera, experiencias a este nivel en escuelas (WAGNER, 2001).

La oferta de formación continúa debe también permitir a los educadores la vivencia de experiencias artísticas y pedagógicas actualizadas para que comprendan la importancia educativa de este dominio en la sociedad contemporánea y actúen en conformidad con las transformaciones sociales y culturales de nuestro tiempo.

En los contextos de enseñanza superior, además de la atención que debe ser depositada en la oferta formativa en esta área, deben también ser creados ambientes estimulantes a la investigación científica, permitiendo así el desenvolvimiento de saberes pedagógicos que permitan ayudar a valorizar pedagógicamente este dominio y auxiliar a los educadores a actuar con confianza en este ámbito. En este sentido es esencial estimular igualmente la creación de más carreras de formación e investigación en educación artística en los niveles del $2^{\circ}$ y $3 \mathrm{er}$ ciclos de la enseñanza superior.

Consideramos también que la adopción de políticas educativas que promuevan un acceso más fácil de los agentes educativos y niños a espacios de arte además de apoyar la propia valoración de la educación artística en el sistema educativo y en el currículo, es una necesidad. Las Metas de Aprendizaje para la Educación Infantil, Básica y Secundaria (2010) han venido a dar respuesta a muchos de los problemas planteados en el decurso de esta investigación. Este 
documento ha venido a exponer los aprendizajes que los niños deberán haber realizado hasta el final de la educación infantil, con el objetivo de alcanzar las condiciones favorables para el éxito escolar indicadas en las Orientaciones Curriculares para la Educación Infantil (Ministerio de la Educación, 1997). Se entiende que este paso del Ministerio de la Educación ha sido significativo para completar aspectos poco explícitos en el ámbito de la Expresión Plástica en las orientaciones curriculares, nombradamente el acceso a la cultura visual y al desarrollo de la sensibilidad estética, aspectos defendidos a lo largo de la investigación. No podemos olvidar que “(...) sólo podemos enseñar por lo que somos. [...] Un profesor que se sienta inseguro, confundido o poco engreído, difícilmente podrá defender el arte” (ARNHEIM, 1997, p. 340). Sin embargo, sería interesante analizar empíricamente qué impacto la definición de metas de aprendizajes en el ámbito de la expresión plástica tendría en la calidad de la acción educativa.

Por último, se espera que este proyecto permita una mejor comprensión y encuadramiento de la expresión plástica en la educación infantil en Portugal. Identificadas las problemáticas y dificultades, dejamos la puerta abierta para que sean dibujados nuevos caminos y para que se mejore sus prácticas. 


\section{REFERENCIAS BIBLIOGRÁFICAS}

ARNHEIM, R. (1997). Para uma psicologia da arte: arte e entropia. Lisboa: Dinalivro.

BARBOSA, A. (2002). Inquietações e Mudanças no Ensino da Arte. São Paulo: Editora Cortez.

BARBOSA, A. (2005). A Imagem no Ensino da Arte. São Paulo: Editora Perspectiva.

BIASOLI, C. (1999). A Formação do Professor de Arte. São Paulo: Papirus Editora.

CAJA, J., BERROCAL, M., \& RAMOS, J. (2003). Un mundo lleno de imágenes. En Badia, M.

et. al. Figuras, Formas, Colores: propuestas para trabajar la Educación Plástica y Visual (pp. 37-44). Barcelona: Editorial Graó.

CARMO, H., \& FERREIRA, M. (1998). Metodologia da Investigação. Lisboa: Universidade Aberta.

EFLAND, A. (2000). El currículum en red: una alternativa para organizar los contenidos de aprendizaje. Kikirikí. (42/43) 96-109.

EFLAND, A. (2002). Una historia de la educación del arte: Tendencias intelectuales y sociales en enseñanza de las artes visuales. Barcelona: Paidós.

EFLAND, A. (2004). Arte y Cognición: la integración de las artes visuales en el currículum. Barcelona: Octaedro.

FREEDMAN, K., \& STUHR, P. (2004). Curriculum change for the 21st century: visual culture in art education. En Eisner, E. \& Day, M. (Org.). Handbook of Research and Policy in Art Education (pp. 815- 828). New Jersey: Lawrence Erlbaum Associates.

HERNÁNDEZ, F. (1997). Cultura Visual y Educación. Sevilla: MCEP.

HERNÁNDEZ, F. (1998). Transgressão e Mudança na Educação: os projectos de trabalho. Porto Alegre: ArtMed. 
HERNÁNDEZ, F. (2000). Cultura visual, mudança educativa e projectos de trabalho. Porto Alegre: Artmed Editora.

HERNÁNDEZ, F. (2003). Educación y Cultura Visual: repensar la educación de las artes visuales. En BADIA, M. et. al. Figuras, Formas, Colores: propuestas para trabajar la Educación Plástica y Visual (pp. 45-52). Barcelona: Editorial Graó.

HOHMANN, M., \& WEIKART, D. (2003). Educar a criança. Lisboa: Fundação Calouste Gulbenkian.

KATZ, L., \& CHARD, S. (1997). A Abordagem de Projecto na Educação de Infância. Lisboa: Fundação Calouste Gulbenkian.

LOPEZ GARCIA, C. (2003). Acerca de la organización de los lenguajes artísticos. En Badia, M. et. al. Figuras, Formas, Colores: propuestas para trabajar la Educación Plástica y Visual (pp. 21-28). Barcelona: Editorial Graó.

MARTINS, M. (2002). Conceito e Terminologia - Aquecendo uma transforma-ação: atitudes e valores no ensino da arte. En Barbosa, A. (Org.). Inquietações e Mudanças no Ensino da Arte (pp. 49-60). São Paulo: Cortez.

MINISTÉRIO DA EDUCAÇÃO (1997). Orientações Curriculares para a Educação Préescolar. Lisboa: Ministério da Educação - Departamento da Educação Básica.

OLIVEIRA, M., CRUZ, S., \& PECHINCHA, M. (2004). Expressões de Comunicação: O desenho de uma linha de investigação. Revista Cadernos de Estudo (1), 12 - 21. Porto: Escola Superior de Educação de Paula Frassinetti.

PARK, J. (2006, Marzo). Critical Thinking and Visual Culture Art Education. Conferência apresentada na Conferência da International Society of Education through Art. Congresso International InSEA. Viseu: InSEA.

PARSONS, M. (2004). Art and Integrated Curriculum. En Eisner, E. \& Day, M. (Org.). Handbook of Research and Policy in Art Education (pp. 775-79). New Jersey: Lawrence Erlbaum Associates. 
PINA, M. (1994). La investigación cooperativa. En Garcia Hoz, V. (Org.). Problemas y métodos de investigación en educación personalizada (pp. 376-403). Madrid: Rialp.

ROLDÃO, M. C. (2000). Formar professores. Os desafios da profissionalidade e o currículo. Aveiro: CIFOP - Universidade de Aveiro.

SOUSA, A. (2009). Investigação em Educação. Lisboa: Livros Horizonte.

STURKEN, M., \& CARTWRIGHT, L. (2001). Practices of looking: an introduction to visual culture. Oxford: Oxford University Press.

VYGOTSKY, L. (1978). Mind in Society. London: Harvard University Press.

\section{WEBGRAFIA}

BARBOSA, A. (2001). Arte/Educación en Brasil: hagamos educadores del arte. En UNESCO. Métodos, Contenidos y Enseñanza de las Artes en América Latina y el Caribe. [http://portal.unesco.org/culture/en/file_download.php/60f2c756fbe436f0e6ad52157ef1b4ae1333 77s.pdf] Brasil. UNESCO. [Consulta: Septiembre de 2011].

WAGNER, T. (2001). Las artes y la creatividad artística. En UNESCO. Métodos, Contenidos y Enseñanza de las Artes en América Latina y el Caribe. Brasil. UNESCO. «http://portal.unesco.org/culture/en/file_download.php/60f2c756fbe436f0e6ad52157ef1b4ae133 377s.pdf» [Consulta: septiembre 2011]. 